\title{
Ethmoidal dural Arteriovenous Fistula- A case report.
}

\author{
Pankaj Raj Nepal ${ }^{1}$, Karuna Tamrakar Karki ${ }^{2}$, Dinesh Kumar Thapa ${ }^{3}$ \\ ${ }^{1}$ Consultant Neurosurgeon and HOD, ${ }^{2}$ Consultant Neurosurgeon, ${ }^{3}$ Registrar, Department of Neurosurgery, B and C Medical \\ college Teaching Hospital and Research Center, Birtamode, Jhapa, Nepal
}

Received: August 01, 2020

Accepted: August 20, 2020

Published: September 1,

2020

Cite this paper:

Nepal PR, Karki KT, Thapa DK. Ethmoidal dural Arteriovenous Fistula- A case report. Journal of Brain and Spine Foundation Nepal. 2020;1(1):33-35.

\section{Correspondence:}

Pankaj Raj Nepal

Deputy Medical Director and Head of Department Department of Neurosurgery

B and C Medical College Teaching Hospital and Research Center, Birtamode, Jhapa, Nepal.

E-mail address: pankajrajnepal@gmail.com

ORCID: https://orcid.org/0000-0002-0489-7666

\section{ABSTRACT:}

Ethmoidal dural arteriovenous fistulas (dAVF) are a rare type of dAVF present in the anterior cranial fossa. There are usually fed by the ethmoidal artery and drains into superior sagittal sinus. Due to its high flow nature, they are considered a challenging case for surgery and usually present with frontal lobe hematoma or seizure. Here, is a similar case report of a 52-year-old gentleman who presented with sequel of frontal lobe hematoma and was managed surgically with clipping of feeder and excision of fistula.

Key words: Arteriovenous fistula, Intracranial pressure, Ophthalmic artery, Superior sagittal sinus.

\section{Introduction:}

There are various classification systems adopted in dural atriovenous fistulas( dAVF), and based on the location one of the types is ethmoidal dAVF or also called anterior cranial fossa dAVF. ${ }^{1,2}$ This type of fistula usually presents with raised intracranial pressure due to bleed in the frontal lobe. The feeding artery in ethmoidal dAVF is usually from the ethmoidal branch of the ophthalmic artery and drains into the superior sagittal sinus via one of the cortical veins.

There are various treatment modalities of such lesions, which range from endovascular to open surgical approach. ${ }^{3,45}$ Due to its location and the risk of occluding the ophthalmic artery, an open surgical approach has been adopted by most of the surgeons. ${ }^{6,7}$

\section{Case summary}

A 52-year-old right-handed gentleman was brought into the emergency department with the complaint of headache for nine days, which was gradually progressive, and got severe for the last few hours. It was associated with multiple episodes of vomiting and was not responding to simple analgesics. It was aggravated by cough and lying down. There was no history of trauma, loss of consciousness, seizure, and fever. On examination he was opening eyes spontaneously, obeying commands and oriented to time, place, and person with intact higher mental function except for urinary incontinence and few apraxias. His pupils were $3 \mathrm{~mm}$ reacting to light with intact cranial nerves except for Frisen's grade III 
papilledema. There was no focal neurological deficit. Cerebellar signs were absent and there was no signs of meningism. There was no history of other comorbidities.

Magnetic Resonance Imaging (MRI) of brain showed around $35 \mathrm{ml}$ of left frontal hematoma of different ages. Magnetic Resonance Angiography (MRA) showed a large conglomeration of vessels in the anterior cranial fossa with its connections to the ethmoidal artery and superior sagittal sinus (Figure 1).
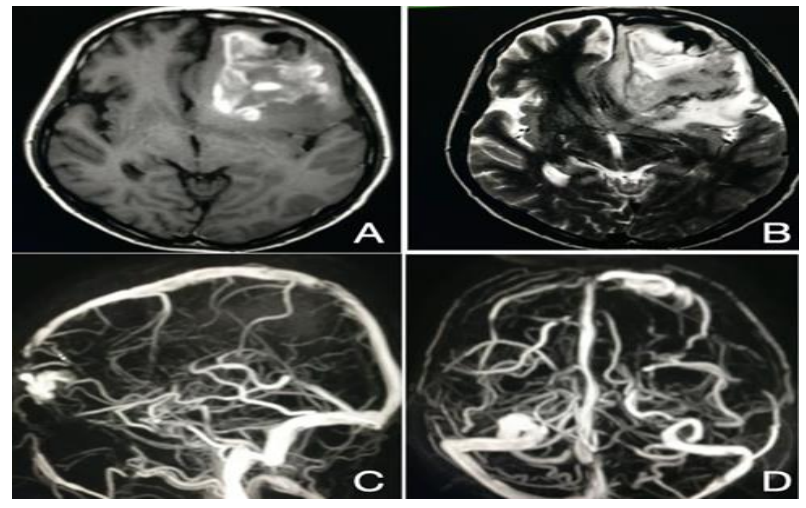

Figure 1: $\mathrm{A}$ and $\mathrm{B}$ are $\mathrm{T} 1$ and $\mathrm{T} 2$ sequence showing different ages of the left frontal hematoma with flow void of dAVF. C and $\mathrm{D}$ are sagittal and axial view of the angiography

He underwent left frontal craniotomy, evacuation of hematoma, and excisions of the fistula with clipping of feeding artery at the base of the anterior cranial fossa. Initially, the procedure was carried out by partial evacuation of hematoma followed by circumferential dissection at the margin of engorged vessels tangentially. Once the feeder and draining vessels were isolated, (Figure 2) the feeder was clipped with titanium straight clip and the remaining parts were excised and the rest of the hematoma was evacuated. The patient was extubated six hours following the surgery and gradually mobilized on subsequent days. He was feeding orally and mobilizing well with no new neurological deficit including vision at the time of discharge (Figure 3).

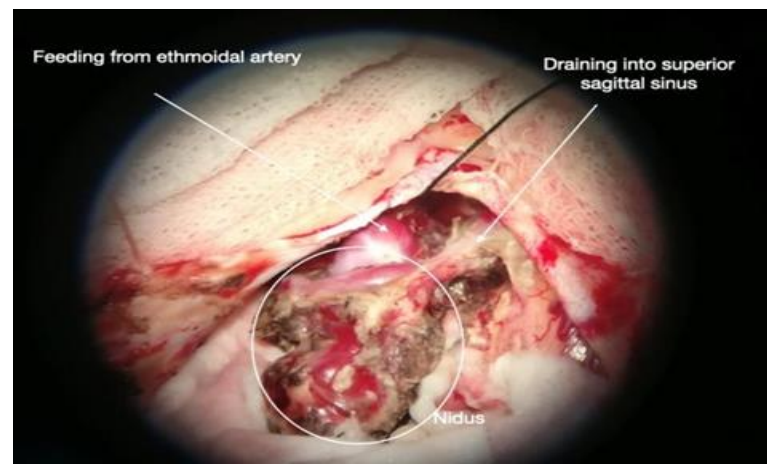

Figure 2: Intraoperative photograph showing feeding artery, draining vein and the nidus

\section{Discussion:}

Ethmoidal dAVF is a rare location for an arteriovenous fistula and they usually present with subdural bleed or intra-parenchymal bleed. Very rarely there are reported cases of these occurring bilaterally. ${ }^{8}$ Most accepted treatment strategies for these types of the lesion are open surgical approach as there is always some mass lesions which needs to be tackled surgically. ${ }^{6,7}$ However, recently there literature suggesting usefulness of endovascular management, which involves either obliteration of the lesion through venous route, or embolization through transarterial route. ${ }^{4,5}$ Though relatively uncommon, there is a greater risk of obliterating the ophthalmic artery when dealing with the lesion through the transarterial route and thus risk in the vision of the patient. Along with the visual complication, the other common complication is recanalization of the fistula. ${ }^{9}$ In this case, there was a significantly large-sized hematoma that needed to be evacuated surgically and hence he was taken up for surgery. Surgery seems to have a better outcome for managing these types of cases though technically challenging, in terms of protecting the vision, and preventing future recanalization. ${ }^{9}$ Multimodality approach has also been described in the literature where embolization is usually combined with the surgical approach. Stereotactic radiosurgery is also used in the 
past with no proper evidence of complete obliteration of the fistula. ${ }^{10}$

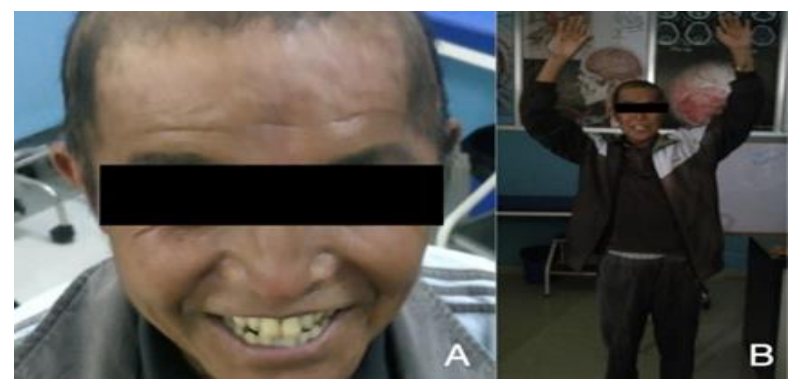

Figure 3: Post- op picture showing no neurological deficit.

When a fistula presents with intracerebral hemorrhage, there is usually a clear plain on the posterior aspect of the fistula and so the surgical dissection is usually tangentially along the lateral walls and much of the care is taken to dissect along the anterior cranial fossa as the feeding artery emerges from the tough dura of the anterior cranial fossa. It is preferred to place a clip to obliterate the feeding artery as coagulation of the vessels might lead to shrinkage of the vessel which might get retracted causing a torrential bleed. ${ }^{11}$ In our case, we clipped the feeder, and then the rest of the fistula was excised easily. In the early steps of dissection, the hematoma was not fully evacuated to prevent intraoperative rupture and to let the working space elevated.

\section{Conclusion:}

dAVF though high flow fistula can be managed with clipping of feeder and excision of the fistula with a better outcome.

\section{References:}

1. Borden JA, Wu JK, Shucart WA. A proposed classification for spinal and cranial dural arteriovenous fistulous malformations and implications for treatment. $\mathbf{J}$ Neurosurg. 1995;82:166-79. https://doi:10.3171/jns.1995.82.2.0166.

2. Cognard C, Gobin YP, Pierot L, Bailly AL, Houdart E, Casasco A, et al. Cerebral dural arteriovenous fistulas: clinical and angiographic correlation with a revised classification of venous drainage. Radiology. 1995 Mar;194(3):671-80. https://doi: 10.1148/radiology.194.3.7862961.

3. Lawton MT, Chun J, Wilson CB, Halbach VV. Ethmoidal dural arteriovenous fistulae: an assessment of surgical and endovascular management. Neurosurgery. 1999 Oct; $45(4): 805-11$. https://doi.org/10.1097/00006123-199910000-00014.

4. Agid R, Terbrugge K, Rodesch G, Andersson T, Söderman M. Management strategies for anterior cranial fossa (ethmoidal) dural arteriovenous fistulas with an emphasis on endovascular treatment. J Neurosurg. 2009 Jan;110(1):79-84. https://doi: 10.3171/2008.6.17601.

5. Defreyne L, Vanlangenhove $P$, Vandekerckhove $T$, Deschrijver I, Sieben G, Klaes R, et al. Transvenous embolization of a dural arteriovenous fistula of the anterior cranial fossa: preliminary results. AJNR Am J Neuroradiol. 2000 Apr;21(4):761-5. Available from: http://www.ajnr.org/content/ajnr/21/4/761.full.pdf.

6. Mayfrank L, Reul J, Huffmann B, Bertalanffy H, Spetzger U, Gilsbach JM. Microsurgical interhemispheric approach to dural arteriovenous fistulas of the floor of the anterior cranial fossa. Minim Invasive Neurosurg. 1999;39:74-77. https://doi: 10.1055/s-20081052221.

7. Meneghelli P, Pasqualin A, Lanterna LA, Bernucci C, Spinelli R, Dorelli G, et al. Surgical treatment of anterior cranial fossa dural arterio-venous fistulas (DAVFs): a two-centre experience. Acta neurochir (Wien). 2017 May;159(5):823-30. https://doi: 10.1007/s00701-017$3107-2$.

8. de San Pedro JR, Pérez CJ, Parra JZ, López- Guerrero AL, Sánchez JF. Bilateral ethmoidal dural arteriovenous fistula: unexpected surgical diagnosis. Clin Neurol Neurosurg. 2010;112(10):903-8. https://doi:10.1016/j.clineuro.2010.07.006

9. Giannopoulos S, Texakalidis P, Alkhataybeh RA, Charisis N, Rangel-Castilla L, Jabbour $\mathrm{P}$, et al. Treatment of ethmoidal dural arteriovenous fistulas: a meta-analysis comparing endovascular versus surgical treatment. World neurosurg. 2019 Aug;128:593-9. https://doi.org/10.1016/j.wneu.2019.04.227.

10. Pollock BE, Nichols DA, Garrity JA, Gorman DA, Stafford SL. Stereotactic radiosurgery and particulate embolization for cavernous sinus dural arteriovenous fistulae. Neurosurgery. 1999 Sep;45(3):459-66; discussion 466-7. https:Ildoi: 10.1097/00006123199909000-00008.

11. Wicks RT, Zhao X, Hardesty DA, Liebelt BD, Nakaji P. Mini-pterional approach for clip ligation of ethmoidal dural arteriovenous fistula. Neurosurg Focus. 2019 Apr 1;46(Suppl_2):V9. https://doi: 